\title{
Assédio moral, ética e sofrimento no trabalho
}

Maria Cristina Cescatto Bobroff ${ }^{1}$, Júlia Trevisan Martins ${ }^{2}$

\section{Resumo}

O assédio moral é um fenômeno complexo e uma realidade no mundo do trabalho. Para que uma ação seja definida como assédio moral, a intenção do assediador, a duração e frequência com que os episódios ocorrem precisam ser investigados. É um tipo de violência que envolve princípios éticos individuais e coletivos e que pode afetar a qualidade de vida dos trabalhadores, levando a doenças físicas, psíquico-emocionais e sofrimento no trabalho. Esta reflexão narrativa define e caracteriza assédio moral relacionando-o à ética; relata suas principais repercussões à saúde dos trabalhadores e comenta brevemente sobre a legislação internacional e nacional sobre este tema.

Palavras-chave: Comportamento social. Saúde do trabalhador. Dano moral. Ética. Estresse psicológico.

\section{Resumen}

\section{Acoso moral, ética y sufrimiento en el trabajo}

El acoso moral es un fenómeno complejo y una realidad en el entorno laboral. Para que una acción se defina como acoso moral, algunos puntos como la intención del acosador, la duración y la frecuencia con que se ocurren deben ser investigados. Éste es un tipo de violencia que implique principios éticos individuales y colectivos y que puede afectar la calidad de vida de los trabajadores, conduciendo a las enfermedades físicas, psíquico-emocionales y sufrimiento en el trabajo. Ésta reflexión narrativa define y caracteriza el acoso moral relacionándolo a la ética; relata sus principales consecuencias a la salud de los trabajadores; $y$, comenta con brevedad acerca de la legislación internacional y nacional sobre este tema.

Palabras-clave: Conducta social. Salud laboral. Daño moral. Ética. Estrés psicológico.

\section{Abstract \\ Moral harassment, ethics and psychological stress in workplace}

The moral harassment is a complex phenomenon and a current reality in the working world. To qualify an action as moral harassment, the harasser's intention, the endurance and frequency must be investigated. It is a violence that involves individual and collective ethical principles that may affect the workers' life quality, leading to physical and psychosomatic illnesses, and work related suffering. This narrative text defines and characterizes moral harassment in its relation to ethics, the main results on workers health, and briefly comments about international and national legislation on this theme.

Key words: Social behavior. Workers health. Moral damage. Ethics. Psychological stress.

1. Doutora crisbob@uel.br 2. Doutora jtmartins@uel.br - Universidade Estadual de Londrina (UEL), Londrina/PR, Brasil.

\section{Correspondência}

Maria Cristina Cescatto Bobroff - Departamento de Enfermagem, Centro de Ciências da Saúde - Avenida Robert Koch, 60, Vila Operária CEP 86039-440. Londrina/PR, Brasil. 
Ao longo da história o processo de trabalho passou por diferentes enfoques. Das relações sob os regimes de escravidão e servidão àquelas sob a égide do trabalho remunerado, o processo de trabaIho galgou diferentes graus de proteção à saúde dos trabalhadores. O advento da Revolução Industrial introduziu a preocupação com a proteção da integridade física da força de trabalho. Com a 1a Guerra Mundial, iniciou-se a preocupação com a qualidade de vida no trabalho e, no final dos anos 60 , abrangeu-se a saúde mental do trabalhador no foco da saúde ocupacional ${ }^{1}$.

Este processo evidencia a adaptação dos seres humanos às modificações ocorridas no mundo em todos os aspectos e, principalmente, no labor - que representa parte considerável da vida humana. Esta acepção conota o trabalho como processo que se estende além da sobrevivência, o que, atualmente, significa considerar trabalho e saúde no trabalho como direitos de cidadania.

Seja compulsório ou como efeito das características da atividade desempenhada, o cotidiano laboral está impregnado de diversos fatores estressantes. Além destas dificuldades inerentes, as atividades laborais estão sujeitas a outro fator que maximiza o estresse: o assédio moral. Também denominado violência moral no trabalho, esta prática milenar só começou a ser visibilizada recentemente, à medida que a emergência das noções de direitos humanos e cidadania permitiram perceber sua recorrência no mundo do trabalho, principalmente nas atividades em que há predomínio de mulheres, como é o caso da enfermagem.

$O$ assédio moral caracteriza-se pela submissão do trabalhador a constantes humilhações e constrangimentos. Se expressa, contudo, em atitudes violentas e sem ética que provocam repercussões negativas na identidade da pessoa assediada, maculando sua noção de dignidade e infringindo seus direitos fundamentais ${ }^{2}$. Desta forma, é importante que os trabalhadores estejam preparados para reconhecer o assédio moral, evitá-lo e combatê-lo.

Assim, esta reflexão narrativa define e caracteriza assédio moral relacionando-o à ética para meIhor compreensão do assédio no contexto do trabaIho; relata suas principais repercussões à saúde dos trabalhadores e comenta brevemente sobre a legislação internacional e nacional sobre este tema, no intuito de auxiliar os profissionais da área da saúde a perceberem o fenômeno no ambiente laboral e, assim, manterem com menor sofrimento sua saúde física e mental, na vida profissional e pessoal.
Definição e relação: assédio moral e ética

Para entender a relação da ética com o assédio moral é fundamental compreender que a origem da palavra ética vem do grego ethos e significa modo de ser. Desta forma, pode ser definida como um conjunto de valores que norteiam o comportamento do homem em relação aos outros homens na sociedade em que vivem, propiciando, assim, o bem-estar social. Portanto, a ética determina a maneira como o ser humano deve se comportar no meio social em que convive ${ }^{3}$.

Por sua vez, o entendimento do assédio moral decorre de estudos científicos no âmbito da Psicologia e da Medicina, que analisaram ocorrências no ambiente de trabalho e seus efeitos sobre a saúde dos indivíduos ${ }^{2}$. De acordo com a Organização Mundial da Saúde (OMS), o fenômeno implica, literalmente, em formar "multiatitudes" ao redor de alguém para atacá-lo ${ }^{4}$. A conceituação e a teorização sobre assédio moral no trabalho são recentes, porém a história, a mitologia e as religiões o remetem à Antiguidade ${ }^{5}$.

O termo assédio moral pode ser substituído por mobbing devido às repercussões causadas à saúde mental dos trabalhadores ${ }^{2,4}$. Este termo foi identificado em 1984 pelo psicólogo alemão Heinz Leymann, e definido como ações repetidas e repreensíveis, ou claramente negativas, dirigidas de maneira ofensiva contra empregados, que podem conduzir ao seu isolamento do grupo no local de trabalho ${ }^{6}$. Embora tenha sido identificado primordialmente pela Psicologia, outra áreas, como a Filosofia, buscam explicações para o assédio moral tendo como enfoque a visão ética sobre o assunto ${ }^{1}$.

$O$ assédio moral é caracterizado pela degradação deliberada das condições de trabalho, visto que, quando surte efeito, é capaz de instaurar um pacto de tolerância e silêncio coletivos quanto à gradativa desestabilização e fragilização da vítima. Esta paulatinamente perde sua autoestima, duvida de si mesma e sente-se mentirosa à medida que se vê desacreditada pelos outros. Dessa maneira, aniquilam-se suas defesas e abala-se progressivamente sua autoconfiança, dificultando ou mesmo impossibilitando o desempenho de suas atividades laborais e às vezes familiares e sociais ${ }^{6,7}$.

Considera-se assédio moral vertical aquele que decorre de conduta abusiva de superior hierárquico para constranger os subalternos, e horizontal quando os trabalhadores, entre si, têm o objetivo de excluir um ou outro colega não desejável ao grupo ${ }^{7}$. 
Há também o mobbing combinado - união do chefe e dos colegas para excluir o indivíduo - e o mobbing ascendente - um ou vários trabalhadores julgamse merecedores do cargo do seu chefe e passam a boicotá-lo ${ }^{8,9}$.

Tais comportamentos podem relacionar-se a vários fatores, entre os quais se destacam a discriminação e a inveja ${ }^{8}$. Sabe-se ainda que o assédio moral já esteve vinculado a fatores de gênero, raciais, sexuais, religiosos, etários, de nacionalidade, capacidade laboral, antecedentes e condições socioeconômicas, e se constitui em prática relacionada à cultura que acontece em todo o mundo. Porém, a maneira de percebê-la pode variar de país para país ${ }^{8}$.

A Organização Internacional do Trabalho (OIT), em conjunto com a OMS, demonstrou em uma pesquisa no ano 2000 que as perspectivas para os próximos 20 anos, para os trabalhadores, são muito pessimistas no tocante aos aspectos psicológicos; afirmando que o estresse, as angústias, os desajustes familiares, o sofrimento no trabalho oriundo de diversas causas e outros danos psíquicos, advindos inclusive do assédio moral, tendem a predominar no ambiente laboral nas próximas décadas ${ }^{8}$. Embora o fenômeno do assédio moral, por si só, não seja uma doença, os efeitos desta prática são capazes de provocá-la. Exemplo clássico de tais repercussões refere-se à ansiedade que o assediado pode apresentar, causada pelo sofrimento a que está sendo submetido e que pode desencadear danos físicos e psicológicos ${ }^{10}$.

Na área da saúde, o fenômeno ocorre da mesma maneira que em outras profissões. Todos os profissionais, inclusive médicos, categoria com grande maioria constituída pelo gênero masculino, podem ser vítimas de distúrbios decorrentes de condições adversas de trabalho. No que tange especificamente a estes profissionais, principalmente aqueles que trabalham em instituições públicas, as condições laborais podem influenciar a percepção e caracterização do assédio moral, podendo ser facilmente confundido com o excesso de trabalho ${ }^{11}$.

De fato, algumas pesquisas ${ }^{10,12}$ destacam que o assédio moral pode ser confundido com o estresse, especialmente naquelas situações em que a carência de profissionais no quadro da instituição implica em sobrecarga individual de trabalho. Nestes casos, o profissional pode conotar o assédio ao estresse e atribuir seus efeitos ao excesso de atividade profissional.

Por isso, há necessidade de se conhecer meIhor o fenômeno e suas repercussões para prevenir e coibir tal violência no trabalho. Alguns autores 7,8 ressaltam, ainda, que o pleno reconhecimento do assédio é imprescindível para cobrar das instituições políticas a responsabilização quanto ao tratamento do trabalhador assediado, visto que o assédio pode gerar distúrbios físicos e mentais, além de comprometer os laços familiares e sociais.

Outro aspecto a ser observado é que muitas empresas mantêm um código de ética na tentativa de coibir atos de assédio moral, mas somente isso não é suficiente. Há que se criar mecanismos de coibição desta violência e implantar um processo de humanização no trabalho criando espaços de discussão, de diálogo, de comunicação efetiva e de enfrentamento para que se possam discutir abertamente os problemas individuais e coletivos dos trabalhadores ${ }^{13}$.

Tais políticas internas são fundamentais para que os casos de assédio não sejam olvidados, acarretando enorme custo humano e social para as instituições, e nem discutidos apenas no âmbito legal, gerando esporádicas indenizações nos casos em que a prática é juridicamente comprovada. Infere-se, então, que o sofrimento psíquico dos trabalhadores na grande maioria das vezes é relegado a segundo plano, visto que se trata de aspectos subjetivos.

\section{Caracterização do assédio moral}

Para a OIT, milhares de trabalhadores sofrem com o assédio moral. Estudo desenvolvido na União Europeia revela que $8 \%$ dos trabalhadores, ou seja, aproximadamente doze milhões de indivíduos, recebem de seus chefes tratamento considerado tirânico ${ }^{8}$. Nesse sentido, apesar de o assédio já ter sido definido há mais de 25 anos, o que se observa, empiricamente, é que o sofrimento psíquico dos trabalhadores é ainda banalizado.

No Brasil, investigação realizada em 97 empresas no Estado de São Paulo, com 2.072 entrevistados, demonstrou que $42 \%$ explicitaram histórias de humilhação no trabalho e que, destes, as mulheres são as vítimas mais frequentes. Outras vítimas comumente acometidas pelo assédio são os negros, os homossexuais, os portadores de necessidades especiais, os trabalhadores acima de 40 anos e aqueles portadores de lesão por esforços repetitivos ${ }^{6,7}$. Disto se deduz que os trabalhadores com tais características precisam estar atentos à possibilidade de estarem sendo vítimas de assédio moral quando suas relações de trabalho caracterizam-se por episódios abusivos ou agressivos constantes. 
O diagnóstico de tais situações sociais é difícil e caracteriza-se por pequenas atitudes direcionadas regularmente ao alvo. Estas atitudes não acontecem de forma brutal, instantânea e perceptível, como se verifica, por exemplo, na tortura física ${ }^{12}$. Assim, práticas hostis e pontuais não se caracterizam, necessariamente, em assédio moral e, muitas vezes, podem decorrer de situações pontuais de tensão que afeta um dos interlocutores, ambos ou mesmo a própria dinâmica de trabalho. Apesar disso, as situações que envolvem alguma hostilidade devem ser objeto de reflexão e análise, visto que podem parecer sem importância, mas esconder uma catástrofe ${ }^{14}$.

Para que ações e atitudes no mundo do trabalho configurem-se em assédio moral devem ser observados alguns critérios: 1) a realização de ato abusivo ou agressivo; 2 ) a repetição, a frequência, a duração destas práticas hostis; 3 ) a intenção do assediador. É preciso considerar a influência dos aspectos culturais e dos objetivos do assediador ${ }^{10}$.

A repetição pode referir-se ao mesmo ato ou à mesma omissão ou, então, a atos e omissões diferenciados. $O$ que importa perceber é se há uma atitude hostil, de abuso ou agressão recorrente, implícita ou explícita. As repetições destas atitudes desestabilizam a vítima, levando-a a desenvolver doenças, comprometendo sua identidade, dignidade e relações afetivas e sociais. É importante reafirmar que a dificuldade de perceber $o$ assédio o torna um risco invisível, porém concreto, nas relações e condições de trabalho ${ }^{7,15}$.

Contudo, a repetição não deve ser considerada de forma isolada, pois pode haver a repetição de atos sem a frequência ou a duração, que também são aspectos fundamentais na caracterização do assédio. Zanetti informa que um único ato, mesmo repetido muitas vezes, pode não ser considerado como assédio moral, mas como violência psíquica, citando como exemplo a calúnia ${ }^{14}$. Para caracterizar a frequência, inerente ao assédio moral, a repetição deve ocorrer ao menos uma vez por semana; caso contrário, o episódio não será considerado assédio moral, conforme suas características atuais em âmbito internacional ${ }^{16}$.

No que concerne à duração, o tempo pode variar de uma semana até um a três anos ${ }^{16}$. Vários estudos ${ }^{7,10,14}$ demonstraram que a duração média dos ataques do assediador é de aproximadamente seis meses. A duração é um aspecto muito importante no que tange à prevenção, pois o estudo de vários casos demonstrou que nenhum deles teria se transformado em assédio se tivessem sido tomadas medidas de intervenção ou prevenção ${ }^{16}$. É fundamen- tal ressaltar que em situações nas quais a violência da agressão é muito intensa não se faz necessário comprovar se o sofrimento da vítima perdurou por um período de seis meses (normalmente utilizado como parâmetro de avaliação).

Como se pode constatar, trata-se de fenômeno bastante complexo, que consorcia fatores de ordem cultural, social, legal e física. Ao analisá-lo, deve-se ter muita cautela e ponderar sobre esses múltiplos aspectos, considerando desde os relacionados ao âmbito jurídico àqueles relativos à saúde. Também é fundamental que o assediado seja assistido por profissionais competentes e capazes de relacionar o dano e estabelecer o nexo causal ao ambiente laboral. Salienta-se que o nexo causal desse tipo de violência está nas condições em que o trabalho é realizado e não à atividade profissional em si ${ }^{11}$.

O cuidado preconizado na definição das situações de assédio moral deve ser intensificado quando se considera que alguns trabalhadores podem não saber que estão sendo assediados, e até neguem a existência da situação, atribuindo as manifestações clínicas a problemas pessoais. Muitas vezes, tal fato se deve ao desconhecimento acerca do fenômeno. Entretanto, há outras nuances a considerar, como, por exemplo, quando o indivíduo imagina estar sendo assediado ou simula situações para obter uma indenização ${ }^{14}$.

Por isso, a OMS ${ }^{4}$ enfatiza a necessidade de diferenciar conflitos saudáveis de assédio moral, para que não ocorram injustiças tanto para os trabalhadores como para os empregadores. Segundo a organização, é indispensável estabelecer a diferença entre confrontos ocasionais, estratégias abertas e francas, comunicação sincera, dentre outras, e as situações de assédio moral, ou seja, organização vertical de poder, comportamento de boicote, estratégias equivocadas e comunicação indireta. Os trabalhadores necessitam ficar atentos aos principais sintomas do assédio moral, que são: crises de choro, insônia, depressão, sede de vingança, sentimento de inutilidade, diminuição da libido, distúrbios digestivos, dor de cabeça, ideia de suicídio, início de alcoolismo, aumento da pressão arterial e tonturas ${ }^{7}$.

É preciso também considerar que o assédio moral manifesta-se de maneira diferenciada em relação aos sexos e decorre de componentes culturais que são explicados sociologicamente. As mulheres são as que mais sofrem intimidação, submissão, piadas grosseiras, comentários acerca de sua aparência física ou do vestuário; para os homens, são mais comuns os comentários maldosos sobre sua virilidade, capacidade de trabalho e de manter a família ${ }^{17}$. 


\section{Assédio moral entre profissionais de saúde}

No que tange ao trabalho dos profissionais de saúde, é essencial frisar a necessidade de estarem especialmente alertas às possíveis situações de assédio moral, vez que suas atividades são, a priori, estressantes. Além disso, há que se salientar como agravante o processo hierárquico dos serviços de saúde, o qual, historicamente, confere primazia aos médicos em detrimento das demais categorias profissionais. Nestas circunstâncias é imprescindível, portanto, redobrar a atenção para identificar possíveis situações de assédio moral.

Este imperativo aplica-se com maior pertinência à enfermagem, categoria para a qual a literatura científica enfatiza a importância de aprender a cuidar de si antes de cuidar do outro, para estar em condições de prestar o cuidado aos pacientes e familiares ${ }^{18}$. Nesta abordagem, reconhecer aquilo que é prejudicial, como o assédio moral, é estratégia indispensável para evitá-lo ou minimizá-lo, tornando a vida mais feliz e íntegra ${ }^{19}$. Além do autocuidado, ressalta-se que o enfermeiro é o líder da equipe de enfermagem e pode também ser o líder da equipe multiprofissional de saúde. Assim, deve estar preparado para receber as queixas dos trabalhadores, identificar possível situação de assédio moral no ambiente de trabalho de sua equipe e, ainda, atuar ativamente junto às equipes e às organizações no intuito de que tal violência não se torne frequente ou relegada a segundo plano.

A identificação dessas situações pode não ser tão fácil porque $o$ assédio moral tende a ocorrer de forma velada, bem como ser alvo de um pacto de tolerância e silêncio entre os profissionais (assediado, assediadores e testemunhas) ${ }^{11}$. Estudo desenvolvido nos serviços de saúde brasileiros indica tal fato, pois constatou que $38,5 \%$ das vítimas desse tipo de violência tiveram a iniciativa de recorrer à chefia imediata para relatar o ocorrido. Porém, em apenas $20 \%$ dos casos foram tomadas as medidas cabíveis ${ }^{20}$.

Disso se depreende que os trabalhadores devem atentar-se com a maneira de se portar e se comunicar no ambiente de trabalho. É também importante que os empregadores implantem e valorizem programas preventivos para a saúde do trabalhador, com vistas a desenvolver um ambiente saudável para a saúde física e mental de todos e incentivar a prática do autocuidado, assegurando, desta maneira, uma perspectiva de qualidade de vida no trabalho e vida social adequada à manutenção da saúde ${ }^{21}$.
Ressalta-se, ainda, que a universidade, como espaço de liberdade e de autonomia de pensamento multidisciplinar, interdisciplinar e transdisciplinar, tem papel fundamental na produção de informação e formação que propiciem a construção e o caminho de agentes sociais em busca de labor e de vida com dignidade e ética. A formação cidadã, voltada a propostas sociais equânimes, tem ainda a finalidade de trazer à tona os reais problemas do mundo do trabaIho em defesa da vida e, assim, superar as vivências marcadas pela dominação, forte coerção, medo, sofrimento, submissão, dentre outros. A universidade tem, portanto, o encargo de estimular sempre ambientes de trabalho que favoreçam a promoção da saúde dos trabalhadores, a prevenção de doenças e a diminuição dos agravos ${ }^{22}$.

É igualmente preciso refletir sobre a concepção da doença na lógica capitalista, na qual a doença é tida como aspecto central, não considerando a subjetividade, como, por exemplo, o sofrimento da pessoa, mas sim a sua capacidade ou incapacidade de produzir cada vez mais ${ }^{23}$.

\section{Legislação sobre assédio moral}

Poucos países criaram leis específicas para o controle jurídico de situações de assédio moral. Atualmente, somente a França e a Argentina aprovaram, em 2002 e 2004, respectivamente, leis específicas. Todavia, há projetos de lei propostos no Chile, Portugal, Uruguai, Suíça e Bélgica ${ }^{24}$.

No Brasil também não há uma lei trabalhista sobre o assunto, embora a tipificação do assédio moral exista. No âmbito federal há alguns projetos de lei sobre assédio moral e coação moral ${ }^{24-26}$. As normas jurídicas aprovadas restringem-se ao funcionalismo público, em sua maioria são leis estaduais aprovadas no Rio de Janeiro ${ }^{27}$, São Paulo ${ }^{28}$, Rio Grande do Sul ${ }^{29}$ e Minas Gerais ${ }^{30}$, além de projetos de lei em tramitação em outros estados ${ }^{24}$.

Denota-se que nos serviços públicos o assédio normalmente não está associado à produtividade, mas sim às disputas de poder. Neste contexto, o assédio está atrelado a uma dimensão psicológica, na qual a inveja e a cobiça levam os indivíduos a controlar o outro e a querer tirá-lo do caminho ${ }^{9}$. Tal fato pode estar diretamente ligado à falta de legislação específica, que não determina a impunidade do assediador ou a falta de proteção do profissional assediado.

Embora o assédio também seja tipificado na regulamentação de alguns municípios, pode-se con- 
siderar que sua regulamentação ainda é deficiente, em vista do número de municípios brasileiros. Assim, pode-se afirmar que desde 2001 até a atualidade são poucas as leis sobre este assunto aprovadas ${ }^{24}$. Desta forma, são extremamente importantes as atualizações na legislação brasileira com a finalidade de minimizar o assédio moral em todos os níveis funcionais nos quais possa ocorrer.

Enfatiza-se que para os demais trabalhadores aplicam-se os princípios gerais de Direito, as normas contidas na Constituição Federal, no Código Civil e na Consolidação das Leis do Trabalho (CLT). Esse arcabouço jurídico procura assegurar aos trabalhadores, de maneira geral, o direito a um ambiente de trabalho saudável que se constitui como parte de uma organização bem estruturada e que valoriza o bem-estar e a qualidade de vida de seus colaboradores ${ }^{9}$.

Nas relações de trabalho regidas pela CLT, além do empregado, o empregador (pessoa física ou jurídica) também pode ser responsabilizado em casos de assédio moral por não evitar ou reprimir condutas indesejáveis. Nesta circunstância, a responsabilidade do empregador é subjetiva, por dolo ou por culpa, mas com culpa presumida, de modo que se inverte o ônus da prova, ou seja, o empregador deve provar que não agiu culposamente ${ }^{31}$.

Outros aspectos das relações de trabalho que merecem destaque são o poder de direção do empregador e o desconhecimento do trabalhador.

O poder de direção confere ao empregador o direcionamento das relações de trabalho, nos limites legais, como características normais das relações entre empregado/empregador. Este engloba a organização do trabalho com o poder disciplinar sobre o trabalhador; o poder de organização das atividades do empregado em consonância com os demais fatores de produção relacionados aos objetivos da empresa; e o poder de controle do empregador, que Ihe confere o direito de fiscalizar o trabalho do empregado (sanções disciplinares) ${ }^{32}$.

Norteiam-se, assim, decisões legítimas de uma relação trabalhista (transferências de setor ou atividade, mudanças de função ou de turno de trabalho etc.), conforme expressas no contrato de trabalho. Da mesma maneira, é natural que o superior expresse críticas construtivas e avaliações sobre o trabalho executado por seus colaboradores, desde que não utilizadas como represália ou punição ${ }^{33}$.

Em paralelo, quando o trabalhador desconhece seus deveres e obrigações, bem como o poder de direção do empregador, situações normais de um processo de trabalho podem ser erroneamente interpretadas como sendo assédio moral.

Entretanto, devido às peculiaridades deste tema, sua recente inovação como categoria moral, a inexistência de regulamentação ampla para tratar o fenômeno e, principalmente, o tradicionalismo da moralidade, que tende a inserir as relações trabaIhistas como pertinentes à submissão de dominação, é imprescindível a reflexão sobre esse aspecto nefasto do ambiente laboral, buscando, assim, promover novos patamares de relações trabalhistas democráticas e saudáveis.

É fato que além da atenção jurídica o trabalhador assediado necessita, principalmente, de apoio por parte das instituições empregadoras, para evitar que os danos persistam. É fundamental resgatar sua autoestima e identidade enquanto sujeito-trabalhador, criando nas instituições um ambiente compativel com os princípios de cidadania.

Desta forma, um ambiente de trabalho pautado na comunicação dialógica e no resgate da humanização no processo laboral traz implícitos os princípios da sociedade democrática ${ }^{13}$. Deve-se reafirmar a não violência, a igualdade de direitos e a equidade nesse ambiente, praticando diariamente a cidadania.

\section{Considerações finais}

Os efeitos da violência moral na vida dos seres humanos são devastadores, em especial no que tange ao desenvolvimento de doenças psíquicoemocionais. É fundamental preservar a saúde mental dos trabalhadores. Um dos caminhos é adotar medidas de prevenção como a criação de ambientes saudáveis e relações de confiança e equidade entre as pessoas; a implantação de um código de ética e/ou de condutas nas instituições; e programas de treinamento para a prevenção de comportamentos violentos no trabalho.

A Constituição Federal aplicada constitui efetivo meio de proteção do trabalhador no que concerne aos princípios e direitos dos cidadãos, aos valores sociais do trabalho, à livre iniciativa, à igualdade de direitos e obrigações entre os homens e as mulheres e à coibição da violação da honra e da imagem do indivíduo.

Não é tarefa das mais fáceis enfrentar o assédio moral e suas consequências. Combatê-lo é uma necessidade e exige a formação de um coletivo multidisciplinar, isto é, a participação dos sindicatos, advogados, médicos do Trabalho, enfermeiros 
do Trabalho, sociólogos, psicólogos e antropólogos, dentre outros profissionais, que possam criar grupos de reflexão sobre esse tema, propiciando um ambiente de labor com menos riscos e violências aos trabalhadores.

Assim, fica explícito que para se obter um ambiente de trabalho saudável deve-se alcançar condições laborais baseadas em princípios morais, éticos e no respeito ao próximo, considerando cada indiví- duo como único, com suas crenças, valores e cultura. É essencial retomar os valores humanos, de toda natureza. Deve haver o comprometimento coletivo com a ética, a solidariedade, o amor ao próximo, a dignidade, a valorização do eu e do outro, a cidadania e o respeito, acima de tudo, com a vida. Com o despertar para esses valores, acredita-se que o assédio moral nos ambientes de trabalho possa ser amenizado e/ou até excluído, ocasionando menos sofrimentos aos trabalhadores.

\section{Referências}

1. Mothé CB. Código de ética nas empresas pode evitar o assédio moral. Consultor Jurídico. [Internet]. 30 nov. 2005 [acesso 15 ago. 2012]. Disponível: http://www.conjur.com.br/2005nov-30/codigo_etica_empresas_evitar_assedio_moral

2. Amato $F$, Casciano $M V$, Lazzeroni $S$, Loffredo A. II mobbing: aspetti lavoristici: nozione, responsabilità, tutele. Milano: Giuffrè Editore; 2002.

3. Motta NS. Ética e vida profissional. Rio de Janeiro: Âmbito Cultural; 1984.

4. Cassitto MG, Fattorini E, Gilioli R, Rengo C. Sensibilizando sobre el acoso psicológico en el trabajo: orientación para los profesionales de la salud, tomadores de decisiones, gerentes, directores de recursos humanos, comunidad jurídica, sindicatos y trabajadores. Milan: OMS; 2004. (Serie Protección de la salud de los trabajadores; $\mathrm{n}^{\circ} 4$ ).

5. Fiorelli JO, Fiorelli MR, Malhadas Junior MJO. Assédio moral: uma visão multidisciplinar. São Paulo: LTr; 2008.

6. Hirigoyen MF. Assédio moral: a violência perversa no cotidiano. $7^{\mathrm{a}}$ ed. Rio de Janeiro: Bertrand Brasil; 2005.

7. Barreto MMS. Violência, saúde, trabalho: uma jornada de humilhações. São Paulo: Educ; 2003.

8. Mothé $\mathrm{CB}$. O assédio moral nas relações de trabalho. Revista de Direito Trabalhista. 2006; 12(3):12-3.

9. Brasil. Ministério da Saúde. Secretaria-Executiva. Subsecretaria de Assuntos Administrativos. Assédio: violência e sofrimento no ambiente de trabalho: assédio moral. Brasília: Ministério da Saúde; 2009. (Série F. Comunicação e educação em saúde).

10. Zanetti R. Assédio moral no trabalho. [Internet]. [acesso 20 ago. 2012]. Disponível: http://www. robsonzanetti.com.br/v3/docs/livro_robson_zanetti_assedio_moral.pdf

11. Abdalla-Filho E. Violência em saúde: quando o médico é o vulnerável. Bioética. 2004;12(2):121-6.

12. Grebot E. Harcélement au travail: identifier, prevenir, désarmorcer. Paris: Eyrolles Éditionsd'Organisation; 2007.

13. Heloani R. Assédio moral: a dignidade violada. Aletheia. 2005;22(1):101-8.

14. Leymann H. La pérsecution au travail. Paris: Éditions du Sueil; 1996.

15. Moura MA. Assédio moral. [Internet]. [acesso 3 jun. 2012]. Disponível: http://www.mobbing.nu/ estudios-assediomoral.doc

16. Nascimento SACM. O assédio moral no ambiente de trabalho. São Paulo: LTr; 2007.

17. Guedes MN. Terror psicológico no trabalho. São Paulo: LTr; 2003.

18. Urasaki MBM. A interconexão da sensibilidade e da razão no cuidar. Rev Paul Enferm. 2001;20(2):411.

19. Dal Pai D, Lautert L. Estratégias de enfrentamento do adoecimento: um estudo sobre o trabalho da enfermagem. Acta Paul Enferm. [Internet]. 2009 [acesso 24 ago. 2012];22(1):60-65. Disponível: http://www.scielo.br/scielo.php?script=sci_arttext\&pid=S0103-21002009000100010\&lng=pt

20. Gasperi P, Radunz V. Cuidar de si: essencial para enfermeiros. Reme Rev Min Enferm. [Internet]. 2006 [acesso 30 ago. 2012];10(1):82-7. Disponível: http://www.cuidardeidosos.com.br/portal/ wp-content/uploads/2010/04/Cuidar-de-si-essencial-para-enfermeiros.pdf

21. Xavier ACH, Barcelos CRV, Lopes JP, Chamarelli PG, Ribeiro SS, Lacerda LS et al. Assédio moral no trabalho no setor saúde no Rio de Janeiro: algumas características. Rev Bras Saúde Ocup. [Internet]. 2008 [acesso 30 ago. 2012];33(117):15-22. Disponível: http://www.scielo.br/pdf/ rbso/v33n117/a03v33n117.pdf

22. Franco T. Karoshi: o trabalho entre a vida e a morte. Caderno CRH. 2002;37(1):141-61.

23. Nardi H, Tittoni J. Subjetividade e trabalho. In: Cattani AD, organizador. Trabalho e tecnologia: dicionário crítico. Porto Alegre: Vozes; 1997.p.240-6.

24. Assédio moral no trabalho. [Internet]. [acesso 15 ago. 2012]. Disponível: http://www. assediomoral.org/spip.php?rubrique3

25. Brasil. Congresso Nacional. Senado. Projeto de Lei $n^{\circ} 80$, de 2009. Altera dispositivos da Lei $n^{\circ}$ 8.666, de 21 de junho de 1993, que "regulamenta o artigo 37, inciso XXI, da Constituição Federal, 
institui normas para licitações e contratos da Administração Pública e dá outras providências", e institui o Cadastro Nacional de Proteção contra a coação moral no emprego [autor senador Inácio Arruda]. [Internet]. 2009 [acesso 26 jan. 2013]. Disponível: http://www.assediomoral.org/spip. php?article524

26. Brasil. Congresso Nacional. Câmara dos Deputados. Projeto de lei $n^{\circ} 4.591 / 2001$. Dispõe sobre a aplicação de penalidades à prática de "assédio moral" por parte de servidores públicos da União, das autarquias e das fundações públicas federais a seus subordinados, alterando a Lei $n^{\circ} 8.112$, de 11 de dezembro de 1990 [autor deputada Rita Camata]. [Internet]. [acesso 26 jan. 2013]. Disponível: http://www.assediomoral.org/spip.php?article83

27. Rio de Janeiro (Estado). Lei $n^{\circ} 3.921$, de 23 de agosto de 2002. Veda o assédio moral no trabalho, no âmbito dos órgãos, repartições ou entidades da administração centralizada, autarquias, fundações, empresas públicas e sociedades de economia mista, do poder legislativo, executivo ou judiciário do estado do Rio de Janeiro. [Internet]. [acesso 24 jan. 2013]. Disponível: http:// www.assediomoral.org/spip.php?article74

28. São Paulo (Estado). Lei $\mathrm{n}^{\circ} 12.250$, de 9 de fevereiro de 2006. Veda o assédio moral no âmbito da administração pública estadual direta, indireta e fundações públicas do estado de São Paulo. [Internet]. [acesso 24 jan. 2013]. Disponível: http://www.eca.usp.br/cipa/lei12250.htm

29. Rio Grande do Sul. Lei Complementar no 12.561, de 12 de julho de 2006. Dispõe sobre assédio moral na administração estadual do Rio Grande do Sul. [Internet]. [acesso 24 jan. 2013]. Disponível: http://www.assediomoral.org/spip.php?article256

30. Minas Gerais. Lei Complementar no 117, de 11 de janeiro de 2011. Dispõe sobre a prevenção e a punição do assédio moral na administração pública estadual de Minas Gerais. [Internet]. [acesso 24 jan. 2013]. Disponível: http://www.assediomoral.org/spip.php?article576

31. Brasil. Ministério da Saúde. Secretaria-Executiva. Subsecretaria de Assuntos Administrativos. Op. cit. p. 13.

32. Spacil DR, Rambo LI, Wagner JL. Assédio moral: a microviolência do cotidiano. [Internet]. 2004 [acesso 24 jan. 2009]. Disponível em: http://www.wagner.adv.br/estudo. php?id=58

33. Hirigoyen MF. Mal-estar no trabalho: redefinindo o assédio moral. Rio de Janeiro: Bertrand Brasil; 2002.

\section{Participação das autoras}

As autoras participaram, em conjunto, de todas as etapas de elaboração do artigo.

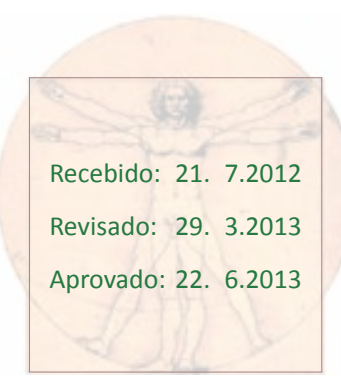

